\title{
Adsorption and Diffusion of Atomic Oxygen and Sulfur at Pristine and Doped Ni Surfaces with Implications for Stress Corrosion Cracking
}

VITALY ALEXANDROV ${ }^{l, 2 *}$, MARIA L. SUSHKO ${ }^{l}$, DANIEL K. SCHREIBER ${ }^{l}$, STEPHEN M. BRUEMMER ${ }^{l}$ AND KEVIN M. ROSSO

${ }^{1}$ Pacific Northwest National Laboratory, Richland, WA 99352, USA, ${ }^{2}$ University of Nebraska-Lincoln, Department of Chemical and Biomolecular Engineering, Lincoln, NE 68588, USA

*Email: valexandrov2@unl.edu

\begin{abstract}
A density-functional-theory modeling study of atomic oxygen/sulfur adsorption and diffusion at pristine and doped $\mathrm{Ni}(111)$ and (110) surfaces is presented. We find that oxygen and sulfur feature comparable adsorption energies over the same surface sites, however, the surface diffusion of sulfur is characterized by an activation barrier about one half that of oxygen. Calculations with different alloying elements at $\mathrm{Ni}$ surfaces show that $\mathrm{Cr}$ strongly enhances surface binding of both species in comparison to Al. These results in combination with previous modeling studies help explain the observed differences in selective grain boundary oxidation mechanisms of $\mathrm{Ni}-\mathrm{Cr}$ and $\mathrm{Ni}-\mathrm{Al}$ alloys.
\end{abstract}

KEYWORDS. Density Functional Theory; Diffusion; Ni Alloys; Oxidation; Sulfidation; Corrosion. 


\section{Introduction.}

Nickel-base alloys represent an important class of structural materials for advanced energy systems due to their ability to withstand a range of aggressive temperatures, pressures and mechanical loadings [1-3]. Nevertheless, these corrosion-resistant metallic alloys can be susceptible to localized attack and cracking leading to component failure. One of the most common degradation modes is due to selective oxidation processes at grain boundaries that lead to intergranular (IG) corrosion, crack initiation and propagation [4-8].

Recent advanced characterization techniques have provided new insights into selective grainboundary oxidation reactions driving IG corrosion and stress corrosion cracking (SCC) of alloys [9-16]. For example, analytical transmission electron microscopy (ATEM) and atom probe tomography (APT) investigations $[17,18]$ demonstrated the formation of isolated discrete oxide precipitates $\left(\mathrm{NiAl}_{2} \mathrm{O}_{4}\right)$ along grain boundaries of $\mathrm{Ni}-4 \mathrm{Al}$ alloys after exposure to $360^{\circ} \mathrm{C}$ hydrogenated water, consistent with oxygen ingress through the metal matrix and classical internal oxidation. On the other hand, grain boundaries of $\mathrm{Ni}-5 \mathrm{Cr}$ alloys exposed to identical high-temperature water conditions exhibit the formation of a continuous IG Cr-rich oxide inconsistent with internal oxidation. These differences can be attributed to the different diffusion behavior of $\mathrm{Al}$ versus $\mathrm{Cr}$, where more facile $\mathrm{Cr}$ diffusion to oxidation fronts in grain boundaries results in a rapid consumption of oxygen, whereas slower Al diffusion allows oxygen ingress and internal oxidation to occur. Our recent first-principles modeling results [19] on the vacancy-mediated diffusion of various alloying metal elements in the bulk and along grain boundaries of $\mathrm{Ni}$ showed a faster $\mathrm{Cr}$ diffusion as compared to $\mathrm{Al}$, especially along the highenergy grain boundaries, thus generally supporting this hypothesis.

Key differences were observed when comparing IG attack of commercial Ni-Cr-Fe alloys (alloy 600) during exposure to high-temperature hydrogenated water with and without surface contamination of sulfur [20,21]. Solid-state grain boundary ingress of sulfur and internal sulfidation was observed when sulfur was present, while oxygen ingress and internal oxidation in the metal grain boundary was not detected in either case. The oxidation/sulfidation behavior documented for this $\mathrm{Ni}-\mathrm{Cr}$ alloy in hydrogenated water was very similar to that found in higher temperature gaseous environments $[22,23]$ where sulfur was discovered to first diffuse into grain boundaries forming $\mathrm{Cr}$ sulfides followed by oxidation reactions that release sulfur deeper into the material. Contrasting the results obtained for oxygen and sulfur cases is not only important for the general understanding of fundamental differences in solid-state electrochemistry of Ni-base alloys, but also because sulfur is a common contaminant in many service environments and an impurity in alloys [24-26]. In order to better understand the 
observed differences in grain boundary oxidation/sulfidation behavior of various Ni-base alloys, it is also important to examine how oxygen and sulfur atoms interact with both pristine and Ni surfaces doped with common alloying elements, an aspect that will be addressed in this study.

Despite a large body of previous experimental information about interfacial oxidation processes promoting SCC in Ni-base alloys, detailed microscopic understanding is still lacking. The inherent complexity of the corrosion/oxidation behavior of Ni-base alloys has triggered a number of computational atomistic studies aimed to elucidate the mechanisms and kinetics of electrochemical reactions, adsorption behavior and species diffusion in the bulk and at interfaces [19,27-33]. Since many degradation processes occur in aqueous environments, first-principles studies have been devoted to understanding of the interactions between water and $\mathrm{Ni}$ surfaces [30,31]. These investigations resulted in a better atomic picture of $\mathrm{H}_{2} \mathrm{O}$ adsorption at various sites on $\mathrm{Ni}$ surfaces, reaction mechanisms of $\mathrm{H}_{2} \mathrm{O}$ dissociation and the associated energy barriers. Interactions between atomic oxygen and particularly sulfur with the Ni surface are still poorly understood. Furthermore, because alloying elements can drastically change the bulk and interfacial properties of $\mathrm{Ni}$, it is crucial to understand how different elements interact with the adsorbed species. Despite general similarities between oxygen and sulfur, recent experimental studies have clearly demonstrated significant differences in their effects on Ni-base alloys [20,21]. Therefore, to develop a better model of early stages of oxidation and sulfidation, it is instructive to contrast the adsorption and diffusion behaviors of oxygen and sulfur and understand how the nature of alloying elements in Ni metal affects interfacial and surface properties. Since the high-energy grain boundaries play a dominant role in oxidation and corrosion behavior of Ni-base alloys, the approach in this paper is to model adsorption reactions and species transport at the Ni surfaces that are characterized by similar open structures. This also allows us to systematically compare the effect of various alloying elements without possible complications arising from atomic reconstructions of the high-energy grain boundaries associated with the presence of alloying and adsorbed species. 


\section{Computational Details.}

Density-functional-theory (DFT) calculations were performed using the VASP code [34,35] within the Perdew-Burke-Ernzerhof (PBE) parametrization of the generalized gradient approximation (GGA) [36] combined with the projector augmented wave (PAW) potentials [37]. All calculations were carried out spin-polarized with a plane wave cutoff energy of $400 \mathrm{eV}$. The Ni(111) surface was modeled as a slab consisting of five Ni layers with $4 \times 4$ expansion of the surface cell resulting in a distance of $9.955 \AA$ between periodic images of adsorbed atomic species. The Ni(110) surface was modeled as a slab with seven Ni layers and $4 \times 2$ surface periodicity with the dimensions of $7.039 \AA \times$ $9.955 \AA$. A vacuum gap of at least $10 \AA$ was used to minimize interaction between surfaces of adjacent slabs. During geometry optimization only the middle Ni layer and the lattice constant were fixed. A lattice constant of $3.5196 \AA$ found from the Ni bulk geometry optimization was used in the study. Optimization of atomic positions was performed until all atomic forces were less than $0.02 \mathrm{eV} / \AA$ and the total energy was converged to better than $10^{-6} \mathrm{eV}$. The Brillouin zone integration was done using a $3 \times 3 \times 1$ Monkhorst-Pack mesh, whereas the use of a $5 \times 5 \times 1$ grid showed only marginal changes in both $\mathrm{Ni}$ surface energies and species adsorption energies. To calculate activation energy barriers for species diffusion at the surfaces, we employed the climbing image nudged elastic band (CI-NEB) method [38]. Species adsorption energies were calculated as $E_{\text {ads }}=E_{\text {surf }+ \text { adsorbate }}-E_{\text {surf }}-E_{\text {adsorbate }}$, where $E_{\text {surf }+ \text { adsorbate }}$ and $E_{\text {surf }}$ are the energies of the surface with and without an adsorbed species (atomic oxygen or sulfur), respectively, and $E_{\text {adsorbate }}$ is the energy of an oxygen or sulfur atom in a $15 \times 15 \times 15 \AA^{3}$ box. This definition implies negative adsorption energies for energetically favorable adsorption processes.

\section{Results and Discussion}

The first step was to consider the adsorption energetics for oxygen and sulfur atomic species over various adsorption sites at the pristine and doped (111) and (110) surfaces of Ni that are known to be the most stable Ni facets. Figures 1 and 2 show different adsorption sites at the Ni(111) and (110) surfaces, while Tables 1 and 2 list the corresponding calculated energies for the adsorption of oxygen and sulfur atomic species at the pristine Ni surfaces. It is seen that at the $\mathrm{Ni}(111)$ surface the hollow-fcc position is the most energetically favorable for both oxygen and sulfur adsorption; this site is slightly more preferable than the hollow-hcp site while the top site is the least favorable. We observe the same trend for the $\mathrm{Ni}(110)$ surface, however, sulfur adsorbs to this surface a little stronger than oxygen on all sites examined. For the $\mathrm{Ni}(110)$ surface we also considered another hollow adsorption site which is near the bridge-long site but moved left into the midst of the triangle (see Figure 2). However, during 
optimization both oxygen and sulfur atomic species converged to the bridge-long position. It is also apparent that the most stable adsorption configurations for both (111) and (110) surfaces are overall quite comparable in energy (-5.87 versus $-5.61 \mathrm{eV})$ for the most favorable adsorption sites, see Tables 1 and 2). In addition, a step was created on the Ni(111) surface by removing half of the uppermost surface Ni atoms. The calculated adsorption energies turned out to be very similar to those obtained for the hollow site at the $\mathrm{Ni}(110)$ surface, being slightly higher for the step on the $\mathrm{Ni}(111)$ surface for both oxygen and sulfur due to the appearance of unsaturated Ni bonds.

Figure 1. Side (left) and top (right) view of the $\mathrm{Ni}(111)$ surface supercell with the corresponding surface adsorption sites. Only half of the slab is shown on the left figure. Color coding helps distinguish different Ni planes.

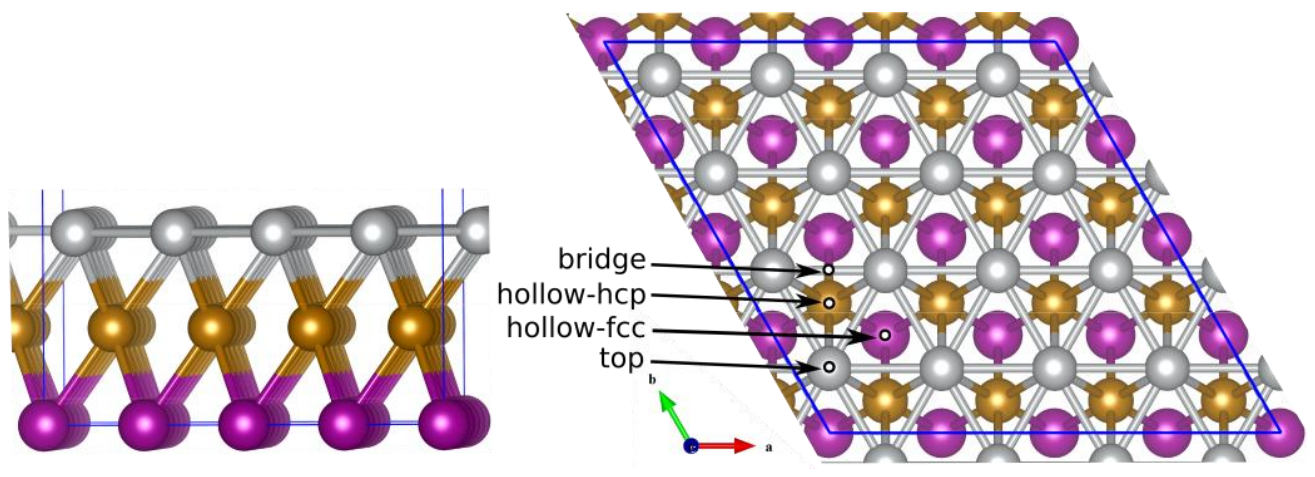

Figure 2. Side (left) and top (right) view of the $\mathrm{Ni}(110)$ surface supercell with the corresponding surface adsorption sites. Only half of the slab is shown on the left figure. Color coding helps distinguish different Ni planes.

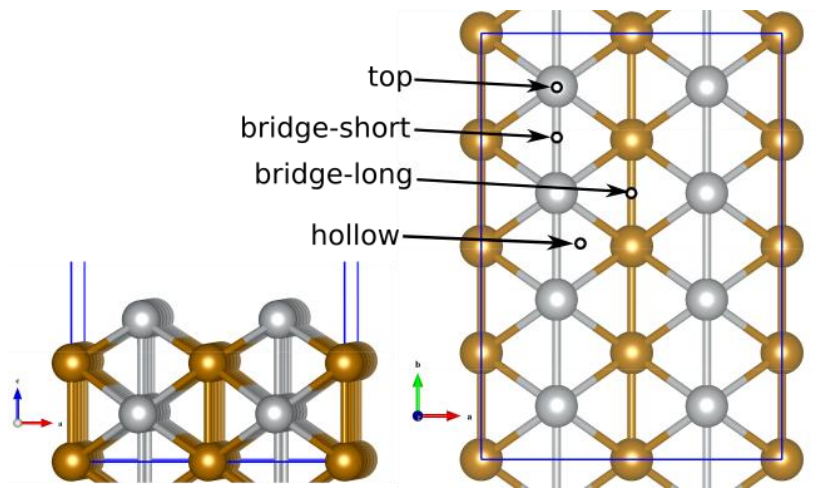


Figure 3. Energy profiles for oxygen and sulfur diffusing at the pristine $\mathrm{Ni}(111)$ surface between two neighboring hollowfcc adsorption sites. Inset shows the position of a diffusing species at the local energy minimum (hollow-hcp site) halfway between initial and final states.

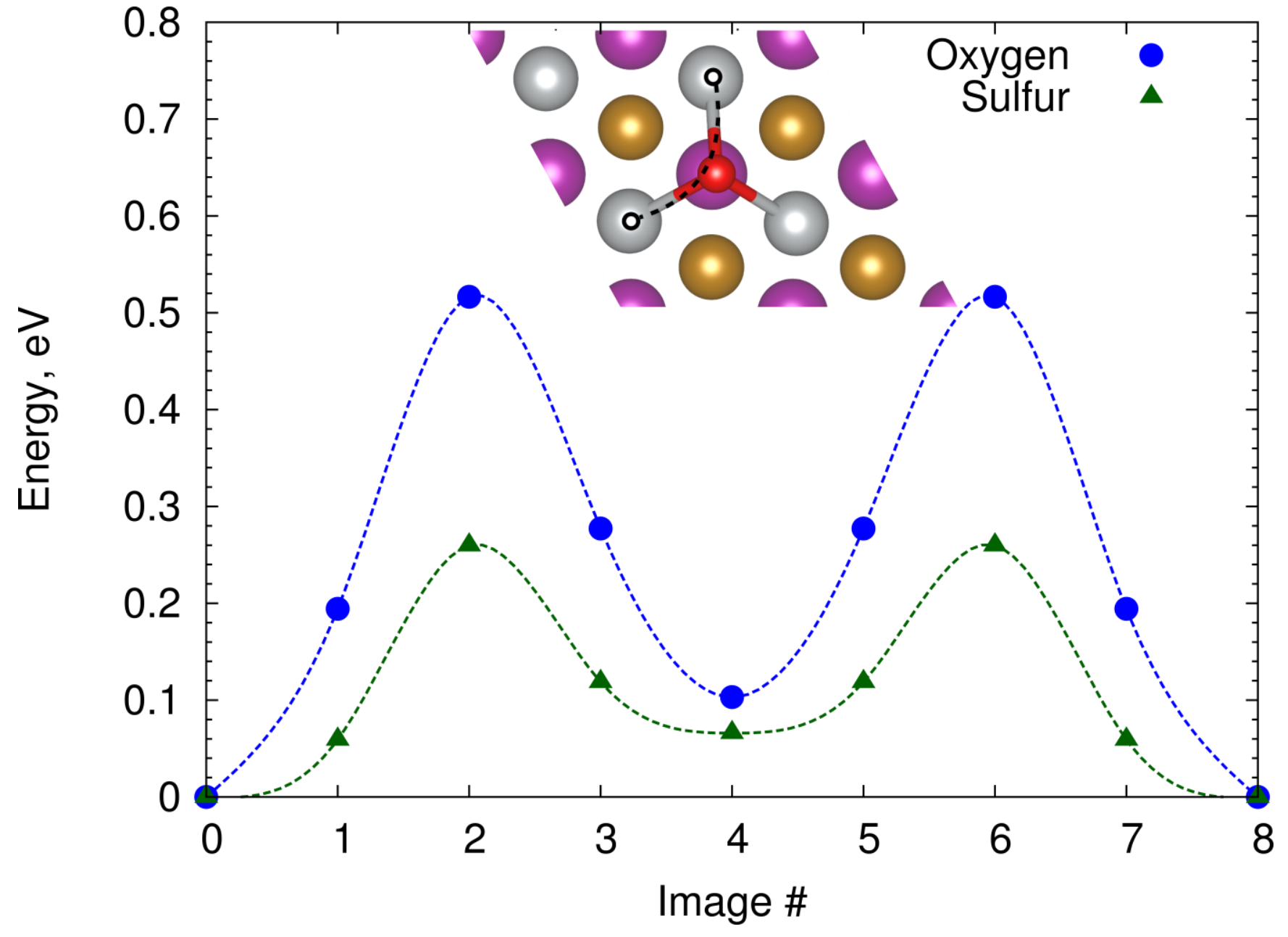


Figure 4. Energy profiles for oxygen and sulfur diffusing at the pristine $\mathrm{Ni}(110)$ surface between the two neighboring hollow adsorption sites.

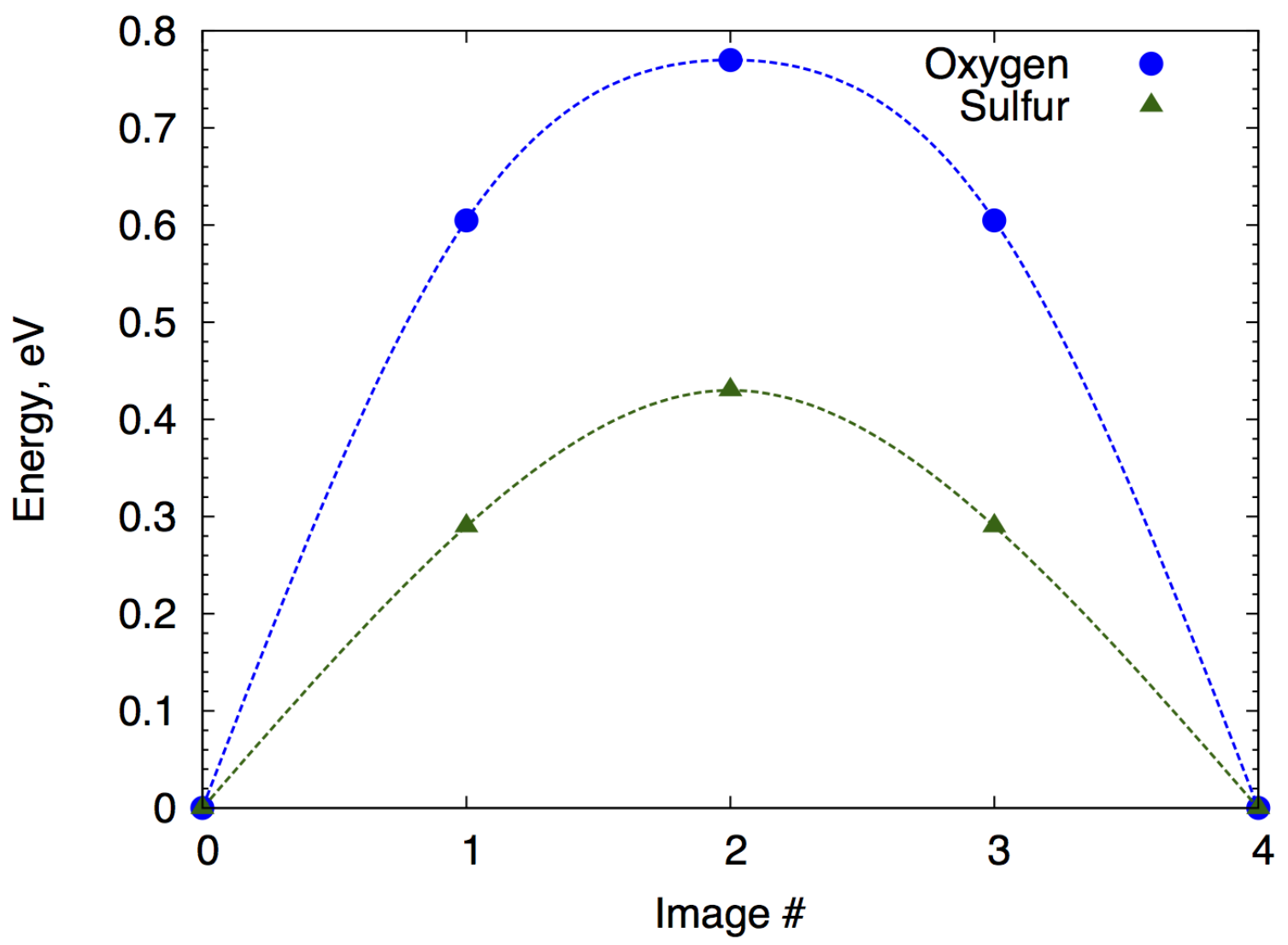

Tables 3 and 4 illustrate how the energies of oxygen/sulfur adsorption change in the presence of an alloying metal element added to the uppermost surface as the nearest neighbor to the adsorbed species for the Ni(111) surface. First of all, we observe that adsorption energies vary substantially depending on the alloying metal element. $\mathrm{Cr}$ and $\mathrm{Mn}$ alloying elements feature the most stable adsorption configurations followed by Fe and Al. In these cases, oxygen and sulfur atomic species are expected to preferentially adsorb on the more reactive alloying element rather than on the Ni matrix atoms. This is, however, not the case for $\mathrm{Cu}$, which is relatively noble compared to $\mathrm{Ni}$, where much less stable oxygen/sulfur adsorption is found in comparison to the host $\mathrm{Ni}$ atoms. The stronger binding of atomic species is consistent with the calculated Bader charges on the alloying element and oxygen/sulfur exhibiting larger ionicity.

An important related issue regards the mobilities of the alloying elements themselves, relative to the rates of oxygen and sulfur diffusion. Our recent first-principles study [19] of vacancy-mediated diffusion across a wide series of alloying metal elements used in Ni-base alloys demonstrated that $\mathrm{Cr}$ and Mn exhibit smaller activation barriers than other metal species considered here, both for the bulk 
case and along grain boundaries (hence their emphasis in the present study). High-energy grain boundaries exhibit remarkably lower activation barriers than those calculated for the bulk and therefore such grain boundaries can serve as efficient conduits for a rapid diffusion of minor alloying elements. Combining these results with the finding of much stronger oxygen/sulfur adsorption on the $\mathrm{Cr}$ (and $\mathrm{Mn}$ ) atoms at $\mathrm{Ni}$ surfaces, we can suggest that the rate-limiting step of selective grain boundary oxidation is the bulk diffusion of alloying metal elements. When $\mathrm{Cr}$ reaches the surface their diffusion should be much more facile along the grain boundaries until they encounter oxygen/sulfur species and form very stable immobile near-surface metal-oxygen or metal-sulfur clusters. These clusters are expected to be precursors for the formation of stable oxide or sulfide precipitates such as $\mathrm{Cr}_{2} \mathrm{O}_{3}$ or $\mathrm{Cr}_{2} \mathrm{~S}_{3}$ at the grain boundary region. Alloying elements other than $\mathrm{Cr}$ and $\mathrm{Mn}$ exhibit a substantially smaller preference for oxygen/sulfur adsorption as compared to the host Ni surface atoms. This is particularly true for $\mathrm{Cu}$ that is characterized by even smaller oxygen/sulfur adsorption energies than the host $\mathrm{Ni}$ atoms, while $\mathrm{Al}$ and Fe exhibit generally similar adsorption energies to Ni. Slower diffusion of these alloying metal elements (versus $\mathrm{Cr}$ and $\mathrm{Mn}$ ) in the bulk and along the grain boundaries further

limits their supply and together with weaker oxygen/sulfur surface adsorption can enable the ingress of oxygen/sulfur into the bulk matrix. These findings help explain oxygen ingress and internal oxidation in a Ni-Al model alloy [17] and the absence of oxygen ingress and internal oxidation for Ni-Cr alloys [18].

It is further seen that oxygen and sulfur show comparable adsorption energetics across the same adsorption sites on the two Ni surfaces. The most prominent difference is the kinetics of oxygen and sulfur diffusion. While it was calculated that oxygen should diffuse much faster than sulfur in bulk $\mathrm{Ni}$ [19], the opposite is found on Ni surfaces. Calculated activation barriers for sulfur surface diffusion are about one half those for oxygen, both on the (111) surface (Figure 3) and on the (110) surface (Figure 4). This suggests that the sulfur supply can be faster than oxygen specifically along high-energy grain boundaries. This finding could partially explain the difference in the observed mechanisms of grain boundary oxidation versus sulfidation in Ni-Cr alloys, where the faster grain boundary diffusion of sulfur as compared to oxygen could enable deeper penetration and internal sulfidation. Conversely, the relatively slow diffusion of oxygen combined with the fast diffusion of $\mathrm{Cr}$ and strong $\mathrm{Cr}$-oxygen binding energy prevents solid-state oxygen ingress into the matrix needed for internal oxidation.

\section{Conclusions}

DFT-calculations have provided new details on the adsorption and diffusion behavior of oxygen and sulfur on both pristine and doped Ni metal surfaces. Both species prefer adsorption at low-energy 
hollow adsorption sites, while sulfur exhibits a significantly lower diffusion barrier than does oxygen. This difference may partially explain the observed tendency of $\mathrm{Ni}-\mathrm{Cr}$ alloys to exhibit internal sulfidation in environmental conditions that do not allow internal oxidation. Comparing different alloying species has also revealed that $\mathrm{Cr}$ and $\mathrm{Mn}$ exhibit the strongest binding energies to both oxygen and sulfur, while $\mathrm{Al}$ and $\mathrm{Fe}$ exhibit binding energies that are relatively similar to that of Ni. Taken together, the results suggest that the relatively slow mobility and weak bonding of $\mathrm{Al}$ with $\mathrm{O}$, in comparison to $\mathrm{Cr}$ diffusivity and $\mathrm{Cr}-\mathrm{O}$ binding energies, enables the experimentally observed internal oxidation of Ni-Al alloys that is not found in similarly tested $\mathrm{Ni}-\mathrm{Cr}$ alloys. 
Table 1. Adsorption energies (in eV) for atomic oxygen and sulfur for various adsorption sites (see Figure 1) at the pristine $\mathrm{Ni}(111)$ surface.

\begin{tabular}{|c|c|c|c|c|c|}
\hline & Top & Hollow-fcc & Hollow-hcp & Bridge & Step \\
\hline Oxygen & -4.02 & -5.87 & -5.76 & -5.76 & -5.67 \\
\hline Sulfur & -4.06 & -5.62 & -5.56 & -5.36 & -5.85 \\
\hline
\end{tabular}

Table 2. Adsorption energies (in $\mathrm{eV}$ ) for atomic oxygen $(\mathrm{O})$ and sulfur $(\mathrm{S})$ for various adsorption sites (see Figure 2) at the pristine Ni(110) surface.

\begin{tabular}{|c|c|c|c|c|}
\hline & Top & Hollow & Bridge-short & Bridge-long \\
\hline Oxygen & -4.35 & -5.61 & -5.55 & -5.40 \\
\hline Sulfur & -4.99 & -5.93 & -6.19 & -5.48 \\
\hline
\end{tabular}

Table 3. Adsorption energies $\mathrm{E}_{\text {ads }}$ (in $\mathrm{eV}$ ) for hollow-fcc and top positions of the adsorbed oxygen atom, as well as metal-oxygen distances $\mathrm{d}(\mathrm{M}-\mathrm{O}$ ) (in $\AA$ ) and atomic charges $q$ for the top configuration over various dopants at the $\mathrm{Ni}(111)$ surface.

\begin{tabular}{|c|c|c|c|c|c|}
\hline & $\mathrm{E}_{\text {ads }}$ (hollow-fcc) & $\mathrm{E}_{\text {ads }}(\mathrm{top})$ & $\mathrm{d}(\mathrm{M}-\mathrm{O})$ & $\mathrm{q}(\mathrm{M})$ & $\mathrm{q}(\mathrm{O})$ \\
\hline $\mathrm{Ni}$ & -5.87 & -4.02 & 1.67 & 0.27 & -0.63 \\
\hline $\mathrm{Al}$ & -6.11 & -4.22 & 1.69 & 1.84 & -1.37 \\
\hline $\mathrm{Cu}$ & -4.70 & -2.34 & 1.73 & 0.26 & -0.72 \\
\hline $\mathrm{Fe}$ & -6.02 & -4.43 & 1.64 & 0.74 & -0.77 \\
\hline $\mathrm{Cr}$ & -9.06 & -8.67 & 1.60 & 1.32 & -0.84 \\
\hline $\mathrm{Mn}$ & -8.83 & -7.73 & 1.61 & 0.93 & -0.74 \\
\hline
\end{tabular}

Table 4. Adsorption energies $\mathrm{E}_{\text {ads }}$ (in $\mathrm{eV}$ ) for hollow-fcc and top positions of the adsorbed sulfur atom, as well as metal-sulfur distances $\mathrm{d}(\mathrm{M}-\mathrm{S}$ ) (in $\AA$ ) and atomic charges $q$ for the top configuration over various dopants at the $\mathrm{Ni}(111)$ surface.

\begin{tabular}{|c|c|c|c|c|c|}
\hline & $\mathrm{E}_{\text {ads }}$ (hollow-fcc) & $\mathrm{E}_{\text {ads }}(\mathrm{top})$ & $\mathrm{d}(\mathrm{M}-\mathrm{S})$ & $\mathrm{q}(\mathrm{M})$ & $\mathrm{q}(\mathrm{S})$ \\
\hline $\mathrm{Ni}$ & -5.62 & -4.06 & 2.01 & 0.02 & -0.46 \\
\hline $\mathrm{Al}$ & -6.76 & -4.87 & 1.69 & 1.63 & -0.80 \\
\hline $\mathrm{Cu}$ & -5.35 & -3.04 & 2.06 & 0.12 & -0.21 \\
\hline $\mathrm{Fe}$ & -5.54 & -4.16 & 2.04 & 0.48 & -0.56 \\
\hline $\mathrm{Cr}$ & -8.34 & -7.17 & 2.03 & 1.03 & -0.59 \\
\hline $\mathrm{Mn}$ & -8.21 & -6.39 & 2.00 & 0.68 & -0.56 \\
\hline
\end{tabular}


Table 5. Adsorption energies $\mathrm{E}_{\mathrm{ads}}$ (in $\mathrm{eV}$ ) for hollow and top positions of the adsorbed oxygen atom, as well as metal-oxygen distances $\mathrm{d}(\mathrm{M}-\mathrm{O}$ ) (in $\AA$ ) and atomic charges $q$ for the top configuration over various dopants at the $\mathrm{Ni}(110)$ surface.

\begin{tabular}{|c|c|c|c|c|c|}
\hline & $\mathrm{E}_{\text {ads }}($ hollow $)$ & $\mathrm{E}_{\text {ads }}($ top $)$ & $\mathrm{d}(\mathrm{M}-\mathrm{O})$ & $\mathrm{q}(\mathrm{M})$ & $\mathrm{q}(\mathrm{O})$ \\
\hline $\mathrm{Ni}$ & -5.61 & -4.35 & 1.65 & 0.37 & -0.69 \\
\hline $\mathrm{Al}$ & -5.98 & -4.59 & 1.67 & 2.10 & -1.31 \\
\hline $\mathrm{Cu}$ & -4.78 & -2.76 & 1.71 & 0.30 & -0.70 \\
\hline $\mathrm{Fe}$ & -5.76 & -5.08 & 1.63 & 0.77 & -0.77 \\
\hline $\mathrm{Cr}$ & -6.70 & -6.48 & 1.60 & 1.38 & -0.86 \\
\hline $\mathrm{Mn}$ & -5.82 & -5.27 & 1.61 & 1.02 & -0.79 \\
\hline
\end{tabular}

Table 6. Adsorption energies $\mathrm{E}_{\mathrm{ads}}$ (in $\mathrm{eV}$ ) for hollow and top positions of the adsorbed sulfur atom, as well as metal-sulfur distances $\mathrm{d}(\mathrm{M}-\mathrm{S}$ ) (in $\AA$ ) and atomic charges $q$ for the top configuration over various dopants at the $\mathrm{Ni}(110)$ surface.

\begin{tabular}{|c|c|c|c|c|c|}
\hline & $\mathrm{E}_{\text {ads }}($ hollow $)$ & $\mathrm{E}_{\text {ads }}($ top $)$ & $\mathrm{d}(\mathrm{M}-\mathrm{S})$ & $\mathrm{q}(\mathrm{M})$ & $\mathrm{q}(\mathrm{S})$ \\
\hline $\mathrm{Ni}$ & -5.93 & -4.99 & 2.00 & 0.36 & -0.69 \\
\hline $\mathrm{Al}$ & -5.61 & -3.58 & 2.12 & 2.04 & -1.04 \\
\hline $\mathrm{Cu}$ & -5.49 & -2.98 & 2.04 & 0.16 & -0.52 \\
\hline $\mathrm{Fe}$ & -5.83 & -4.13 & 2.02 & 0.56 & -0.61 \\
\hline $\mathrm{Cr}$ & -6.07 & -4.72 & 2.02 & 1.11 & -0.66 \\
\hline $\mathrm{Mn}$ & -5.86 & -3.47 & 1.99 & 0.78 & -0.62 \\
\hline
\end{tabular}

\section{Acknowledgements:}

This material is based upon research supported by the US Department of Energy (DOE), Office of Science, Office of Basic Energy Sciences, Division of Materials Sciences and Engineering. The computations were performed using the PNNL Institutional Computing Facility at Pacific Northwest National Laboratory (PNNL). PNNL is a multiprogram national laboratory operated for DOE by Battelle. 


\section{REFERENCES.}

[1] T.M. Pollock, S. Tin, Nickel-based superalloys for advanced turbine engines: Chemistry, microstructure, and properties, J. Propulsion and Power 22 (2) (2006), 361-374.

[2] R.W. Staehle, J. A. Gorman, Quantitative assessment of submodes of stress corrosion cracking on the secondary side of steam generator tubing in pressurized water reactors: Part 1, Corrosion 59 (11) (2003), 931-994.

[3] D. Furrer, H. Fecht, Ni-based superalloys for turbine discs, JOM 51 (1) (1999), 14-17.

[4] G.B. Hoflund, W. S. Epling, Oxidation study of a polycrystalline Ni/Cr alloy II, Chem. Mater. 10 (1998), 50-58.

[5] H. Over, A.P. Seitsonen, Oxidation of metal surfaces, Science 297 (2002), 2003-2005.

[6] Z. Xu, K.M. Rosso, S.M. Bruemmer, Metal oxidation kinetics and the transition from thin to thick films, Phys. Chem. Chem. Phys. 14 (2012), 14534-14539.

[7] S.Y. Persaud, R.C. Newman, A review of oxidation phenomena in Ni alloys exposed to hydrogenated steam below $500^{\circ} \mathrm{C}$, Corrosion 72 (2016), 881-896.

[8] S.Y. Persaud, J. Smith, A. Korinek, G.A. Botton, R.C. Newman, High resolution analysis of oxidation in $\mathrm{Ni}-\mathrm{Fe}-\mathrm{Cr}$ alloys after exposure to $315^{\circ} \mathrm{C}$ deaerated water with added hydrogen, Corrosion Science 106 (2016), 236-248.

[9] T. Magnin, J.M. Boursier, D. Noel, R. Rios, F. Vaillant, Proc. $6^{\text {th }}$ Int. Conf. Environmental Degradation of Materials in Nuclear Power Systems - Water Reactors, San Diego, CA, USA (1993).

[10] G. Was, T.M. Angeliu, J.K. Sang, in Proceedings of Specialist Meeting on Environmental Degradation of Alloy 600 , Airie House, VA, April 1993 (Electric Power Research Institute, Palo Alto, CA, 1996), p. 24.

[11] J.S. Fish, N. Lewis, W.J.S. Yang, D.J. Perry, C.D. Thompson, Proc. $8^{\text {th }}$ Int. Symposium on Environmental Degradation of Materials in Nuclear Power Systems - Water Reactors, American Nuclear Society, Amelia Island, FL, p. 266 (1997).

[12] T.M. Angeliu, P.L. Andresen, F.P. Ford, Applying slip-oxidation to the SCC of austenitic 
materials in BWR/PWR environments, Corrosion 98, NACE (1998), 262.

[13] P. M. Scott, Proc. $9^{\text {th }}$ Int. Conf. on Environmental Degradation of Materials in Nuclear Power Systems - Water Reactors, p. 387 (1999).

[14] S.M. Bruemmer, L.E. Thomas, High-resolution analytical electron microscopy characterization of corrosion and cracking at buried interfaces, Surface and Interface Analysis 31 (7) (2001), 571-581.

[15] K. Airoka, T. Yamada, T. Miyamoto, M. Aoki, Intergranular stress corrosion cracking growth behavior of Ni-Cr-Fe alloys in pressurized water reactor primary water, Corrosion 70 (2014), 695-707.

[16] M. Kanzaki, Y. Masaki, T. Kudo, Effect of Cr and Ni on Stress Corrosion Cracking Susceptibility in Ni-Cr-Fe Alloys Under Simulated Pressurized Water Reactor Primary Conditions, Corrosion 71 (2015), 1027-1035.

[17] D.K. Schreiber, M.J. Olszta, S.M. Bruemmer, Directly correlated transmission electron microscopy and atom probe tomography of grain boundary oxidation in a Ni-Al binary alloy exposed to high-temperature water, Scripta Mater. 69 (7) (2013) 509-512.

[18] D.K. Schreiber, M.J. Olszta, S.M. Bruemmer, Grain boundary depletion and migration during selective oxidation of $\mathrm{Cr}$ in a $\mathrm{Ni}-5 \mathrm{Cr}$ binary alloy exposed to high-temperature hydrogenated water, Scripta Mater. 89 (2014) 41-44..

[19] V. Alexandrov, M.L. Sushko, D.K. Schreiber, S.M. Bruemmer, K.M. Rosso, Ab initio modeling of bulk and intragranular diffusion in Ni alloys, J. Phys. Chem. Lett. 6 (2015) 1618-1623.

[20] D.K. Schreiber, M.J. Olszta, D.W. Saxey, K. Kruska, K. Moore, S. Lozano-Perez, S.M. Bruemmer, Examinations of Oxidation and Sulfidation of Grain Boundaries in Alloy 600 Exposed to Simulated Pressurized Water Reactor Primary Water, Microscopy and Microanalysis 19 (3) (2013) 676-687.

[21] D.K. Schreiber, M.J. Olszta, L.E. Thomas, S.M. Bruemmer, Proc. $16^{\text {th }}$ Int. Conf. on Environmental Degradation of Materials in Nuclear Power Systems - Water Reactors, NACE, International, Asheville, North Carolina, p. 121 (2013).

[22] C.J. Spengler and R. Viswanat, Effect of sequential sulfidation and oxidation on propagation of sulfur in an 85 Ni-15 Cr alloy, Metall. Trans. 3 (1) (1972) 161. 
[23] R.Z. Zhu, M.J. Guo and Y. Zuo, A study of the mechanism of internal sulfidation - internal oxidation during hot corrosion of Ni-base alloys, Oxid. Met. 27 (1987) 253-265.

[24] J.K. Heuer, P.R. Okamoto, N.Q. Lam, J.F. Stubbins, Relationship between segregation-induced intergranular fracture and melting in the nickel-sulfur system, Appl. Phys. Lett. 76 (2000) 3403-3405.

[25] S. Kobayashi, S. Tsurekawa, T. Watanabe, G. Palumbo, Grain boundary engineering for control of sulfur segregation-induced embrittlement in ultrafine-grained nickel, Scr. Mater. 62 (2010) 294-297.

[26] G. Schusteritsch, E. Kaxiras, Sulfur-induced embrittlement of nickel: a first-principles study, Modelling Simul. Mater. Sci. Eng. 20 (2012) 065007.

[27] E.H. Megchiche, M. Amarouche, C. Mijoule, First-principles calculations of the diffusion of atomic oxygen in nickel: thermal expansion contribution, J. Phys.: Condens. Matter 19 (2007) 296201296208.

[28] J.D. Tucker, R. Najafabadi, T.R. Allen, D. Morgan, Ab initio-based diffusion theory and tracer diffusion in Ni-Cr and Ni-Fe alloys, J. Nucl. Mater. 405 (2010) 216-234.

[29] C.Z. Hargather, S.L. Shang, Z.K. Liu, Y.A. Du, A first-principles study of self-diffusion coefficients of fcc Ni, Comput. Mater. Sci. 86 (2014) 17-23.

[30] N.K. Das, I. Tirtom, T. Shoji, A multiscale modelling study of Ni-Cr crack tip initial stage oxidation at different stress intensities, Mater. Chem. and Phys. 122 (2010) 336-342.

[31] N.K. Das, T. Shoji, A density functional study of atomic oxygen and water molecule adsorption on Ni(111) and chromium-substituted Ni(111) surfaces, Appl. Surf. Sci. 258 (2011) 442-447.

[32] N.K. Das, T. Shoji, Early stage oxidation of Ni-Cr binary alloy (111), (110) and (100) surfaces: A combined density functional and quantum chemical molecular dynamics study, Corrosion Science 73 (2013) 18-3.

[33] M.L. Sushko, V. Alexandrov, D.K. Schreiber, K.M. Rosso, S.M. Bruemmer, Multiscale model of metal alloy oxidation at grain boundaries, J. Chem. Phys. 142 (2015) 214114-214121.

[34] G. Kresse, J. Hafner, Ab initio molecular dynamics for open-shell transition metals, Phys. Rev. B 48 (1993) 13115-13118. 
[35] G. Kresse, J. Hafner, Ab initio molecular dynamics simulation of the liquid-metal amorphoussemiconductor transition in germanium, Phys. Rev. B 49 (1994) 14251-14269.

[36] J. P. Perdew, K. Burke, M. Ernzerhof, Generalized gradient approximation made simple, Phys. Rev. Lett. 77 (1996) 3865-3868.

[37] P. E. Blöchl, Projector augmented-wave method, Phys. Rev. B 50 (1994), 17953-17979.

[38] G. Henkelman, B. P. Uberuaga, H. Jonsson, A climbing image nudged elastic band method for finding saddle points and minimum energy paths, J. Chem. Phys. 113 (22) (2000) 9901-9904. 